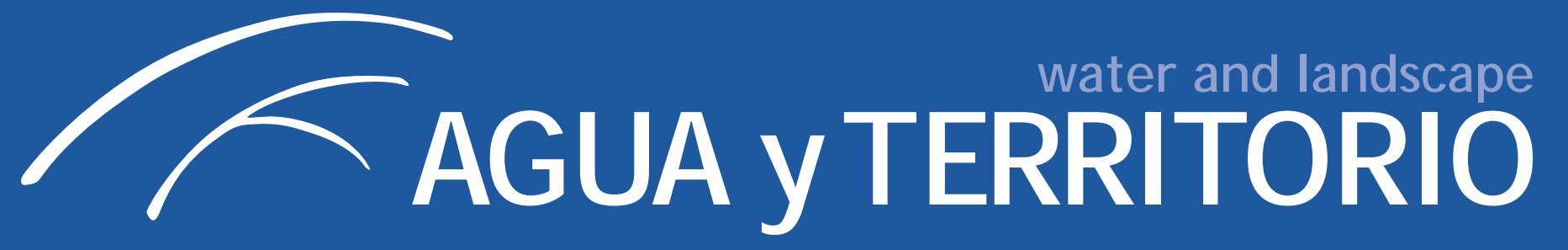

\title{
VI Reunión de la Red WATERLAT-GOBACIT "Agua, violencia y utopías. ¿Cuáles son las prioridades para construir una política hídrica igualitaria?"
}

\author{
Organiza: WATERLAT - GOBACIT - Universidad de Caldas \\ Lugar de celebración: Universidad de Caldas \\ Manizales, Colombia, 27-31 de octubre de 2014
}

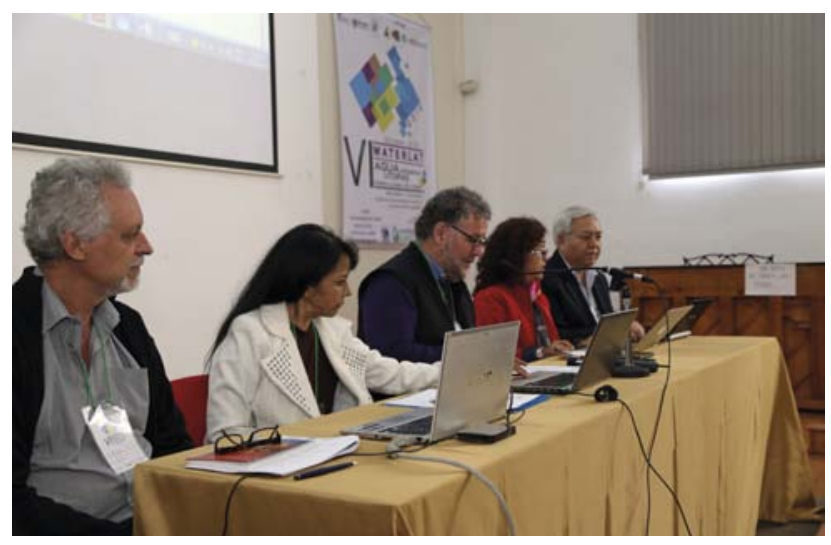

La VI Reunión abordó las relaciones entre "agua", "violencia" y "utopía" por una serie de razones que exceden nuestra capacidad de enumeración. Más de ciento cuarenta investigadores, estudiantes, especialistas, activistas, representantes de movimientos sindicales y organizaciones sociales, ente otros actores, participaron en nuestra reunión para discutir este tema, desde una diversidad de perspectivas e intereses materiales, intelectuales y políticos, a partir de un rango de problemas conceptuales y prácticos, y proviniendo de diferentes contextos culturales, nacionales, regionales y locales, procedentes de 17 países de las Américas y de Europa. La reunión proveyó un espacio de debate con discusiones y reflexiones colectivas que contribuyeron a responder nuestra pregunta central: ¿Cuáles son las prioridades para construir una política hídrica igualitaria?

\section{¿Por Qué VIOLencia?}

Waterlat-Gobacit tiene una serie de objetivos y prioridades bien definidos, cuyo eje central es el de contribuir a desentra- ñar, describir, explicar y confrontar el carácter capitalista de la política y la gestión del agua en sus distintos aspectos y dimensiones. Es decir, entre las muchas cuestiones que podrían tratarse, a Waterlat-Gobacit le interesa profundizar nuestro entendimiento de los procesos y mecanismos que permiten explicar con mayor precisión lo que podríamos denominar "el estado del agua", que cada vez con más claridad refleja el estado del poder social. Este estado del poder, que se refleja en el estado del agua, es fundamentalmente el estado del orden capitalista que, de diversas formas y articulado con otros órdenes en complejas formaciones sociales, prevalece y continúa expandiéndose y arraigándose a escala planetaria. Este es un sistema social que, históricamente, se ha fundado en la producción y reproducción de la violencia sistemática como mecanismo de control, de ordenamiento, de jerarquización, de los seres vivos, de los objetos materiales y de los elementos constitutivos de la vida, notoriamente el agua. No es que la violencia, claramente, sea una prerrogativa del orden capitalista, ni que ese orden se sirva única o principalmente de la violencia como mecanismo, no necesariamente al menos y ciertamente no todo el tiempo. Pero la violencia, en última instancia, es un mecanismo decisivo, fundamental, en los procesos de producción y reproducción del orden social capitalista, del estado del poder y, en relación a nuestro tema central, del estado del agua.

\section{ViOLENCIA COMO CONCEPTO SOCIOLÓGICO}

No hablamos de violencia a partir de juicios de valor subjetivos, que podemos tener a nivel individual o colectivo. En este último sentido, "violencia" tiende a tener una valoración negativa, frecuentemente asociada con las cualidades que un actor, normalmente desde una posición de poder o autoridad, otorga 


\section{Reunión de la Red WATERLAT-GOBACIT "Agua, violencia y utopías. ¿Cuáles son las prioridades para construir una política hídrica igualitaria?"}

0 asocia con el concepto. Por ejemplo, como en el vocabulario dominante en los medios de comunicación de masas, en los que se habla de violencia "criminal", "terrorista", "genocida", etc. La reunión se propuso suspender, por así decir, nuestras apreciaciones valorativas en relación a determinados tipos de violencia para poder compartir un espacio de reflexión sobre las relaciones entre "agua", "violencia" y "utopías".

En este sentido, una definición clásica de "violencia" es que la misma consiste en la ruptura de un orden mediante el uso de la fuerza. Podemos decir, si partimos de esa definición, que la dinámica capitalista se caracteriza por el ejercicio sistemático de la violencia en la ruptura de órdenes socio-naturales, pero también en su reconstitución, reordenamiento y rejerarquización; violencia destructiva pero también violencia creativa. Por lo tanto, nos preocupa no solamente entender y explicar el papel de la violencia en los procesos destructivos y sus consecuencias, como puede ser la destrucción de las condiciones de vida de comunidades enteras por la construcción de megaproyectos hidráulicos, un tema al que se aboca específicamente nuestra Área Temática 2 , sino también hacer inteligible la función de la violencia en los procesos de emergencia de nuevos órdenes socio-naturales, como pueden ser los territorios hidrosociales que son el objeto de nuestra Área Temática 6.

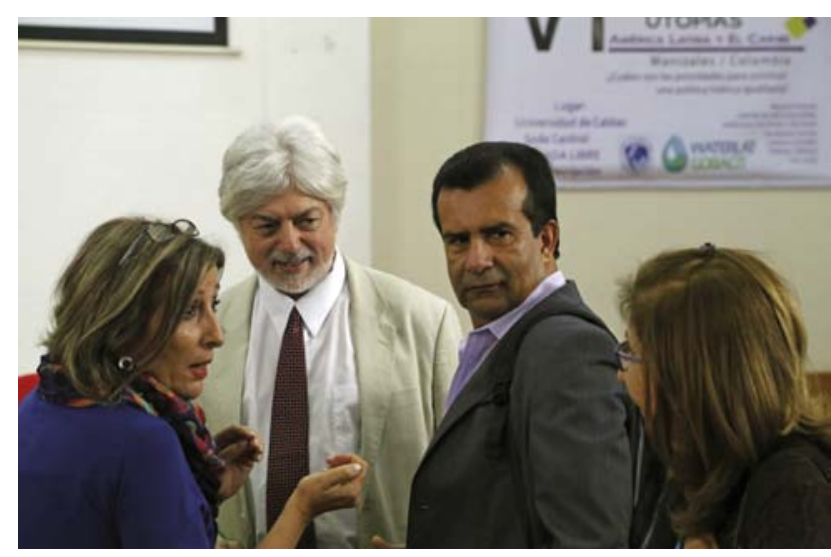

Los trabajos que se presentaron y debatieron en nuestra reunión abordaron un amplio rango de dimensiones y formas de violencia registradas en relación a la política y la gestión del agua. Por una parte, las formas más extremas de la violencia directa, ya sea en la represión brutal de pequeñas poblaciones rurales que resisten la expropiación de sus tierras para la construcción de grandes obras hidráulicas o para expandir la acumulación originaria de los bienes naturales, 0 en el ataque, incluyendo el asesinato, a activistas ambientales, sindicales y otros líderes sociales que luchan por la defensa del agua como un bien común, como un bien público, como un derecho ciudadano, como un derecho humano, o que defienden sus condiciones de vida a partir de algún otro marco de referencia interpretativo o valorativo, como pueden ser los derechos de las comunidades originarias, los derechos de la naturaleza, etc. Por otra parte, las formas estructurales, frecuentemente invisibilizadas, de la violencia institucionalizada, muchas veces a la vez legal e ilegítima, que produce y reproduce desigualdades, exclusiones e injusticias en el acceso al agua y a sus servicios o en la distribución del sufrimiento de los impactos de la degradación o la destrucción del ciclo hidrológico y de los cuerpos de agua ya sea mediante la contaminación o la producción artificial de la escasez, temas analizados en el marco de nuestras Áreas Temáticas 2, 3, 4, 5 y 6, 0 la generación social de desastres nominalmente "naturales", procesos a los que se dedica nuestra Área Temática 8.

Estas y otras formas de violencia constitutivas de lo que hemos denominado aquí "el estado del agua", tienen dimensiones materiales, culturales, intelectuales, simbólicas y emocionales, entre otras, aspectos que fueron debatidos en muchos de los trabajos presentados en nuestra reunión. Una preocupación central de nuestras discusiones ha sido el papel de esas diferentes formas y dimensiones de la violencia en los procesos de deshumanización, marginalización, precarización, vulnerabilización, etc., a los que hemos denominado genéricamente como la producción social de la indefensión, es decir, del desarme intelectual, moral y material, de la expropiación a una parte substantiva de la humanidad de su capacidad para defender sus condiciones de existencia.

\section{¿Por QUÉ UTOPÍAs?}

Señalábamos antes que la dinámica del orden social capitalista no solamente tiene en la violencia un mecanismo de ruptura y destrucción sino también de recreación, reordenamiento y rejerarquización de órdenes socio-naturales, incluyendo el proceso de desarme, la producción de la indefensión. Sin embargo, la profundización y expansión del orden capitalista históricamente ha generado también permanentes y recurrentes resistencias y luchas contra la dinámica expropiadora del sistema. Muchas veces, esas resistencias y luchas han sido alimentadas por proyectos histórico-sociales que procuran construir alternativas superadoras del orden social dominante. En ese sentido rescatamos el concepto de "utopías", en plural, reconociendo la existencia de una amplia gama de idealizaciones e intentos de poner en práctica transiciones a formas de organización social alternativas superiores al orden existente. No reificamos el concepto de "utopía" ni dimos centralidad en nuestra reunión al intenso debate existente sobre el papel de las utopías, las anti-utopías o las distopías en la sociedad contemporánea, lo que nos hubiera apartado del foco central de nuestro tema. Por lo tanto, utilizamos "utopías" en el contexto de nuestra reunión para referirnos a la capacidad humana de transcender los límites aparentemente inamovibles de los sistemas sociales "actualmente existentes", de imaginar y poner en acción alternativas que se entienden como superadoras de las condiciones actuales. En este sentido, el concepto de "utopías" permite también capturar la emergencia, no planeada ni controlada, de procesos sincréticos de transformación social que surgen de las resistencias y luchas y que asumen una gran diversidad de formas y estrategias, en gran medida porque responden a una multidiversidad de actores, intereses y proyectos históricosociales, frecuentemente en contradicción y muchas veces incompatibles entre sí. Es decir, en el contexto de nuestra reunión utilizamos el concepto de "utopías" en un sentido sociológico, 


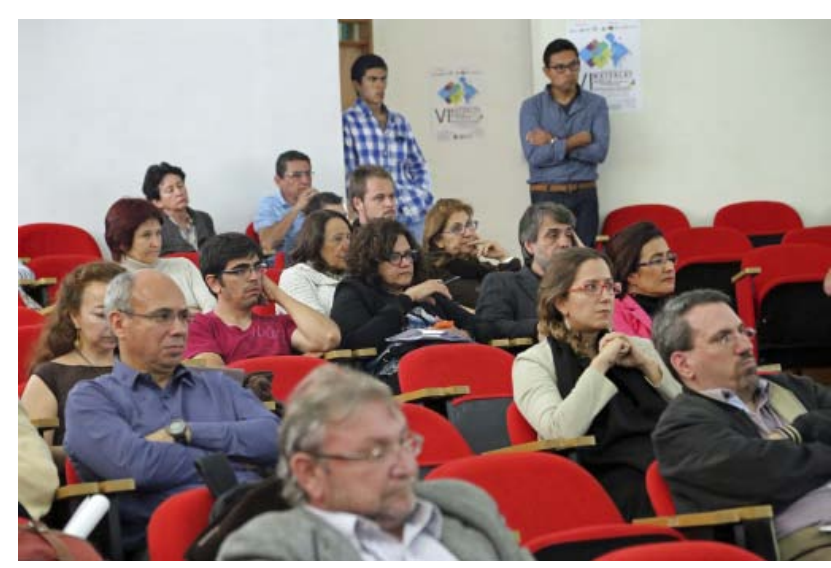

para hacer referencia a esos verdaderos laboratorios de transformación social que identificamos en las resistencias y las luchas orientadas a la superación de las desigualdades e injusticias que caracterizan al "estado del agua" que vivimos. Un foco de interés central en nuestra reunión fueron las utopías inspiradas por la lucha incesante de quienes procuran contribuir a la emergencia de órdenes socio-naturales fundados en el ideal de la igualdad.

La reunión cumplió ampliamente su objetivo de generar un espacio de discusión, intercambio, debate y generación colectiva de proyectos y productos concretos, orientados a responder la pregunta central de nuestro evento: ¿Cuáles son las prioridades para construir una política hídrica igualitaria?

En este sentido, presentamos a continuación algunas decisiones estratégicas que han sido tomadas y una síntesis de las principales conclusiones del encuentro, que procuran dar una respuesta a nuestra pregunta central. También se hicieron algunas declaraciones y manifestaciones de apoyo, reclamo y denuncia referidas a problemas concretos que recibieron prominencia en nuestros debates.

\section{Decisiones Estratégicas}

La Red WATERLAT-GOBACIT y la Internacional de Servicios Públicos (ISP) acordaron establecer una alianza estratégica para el fortalecimiento mutuo de sus capacidades para confrontar las amenazas que afectan al proceso de democratización de la política y la gestión del agua. Principalmente, se busca fortalecer la interacción entre los académicos, las organizaciones de trabajadores, del sector público, de movimientos sociales urbanos campesinos, indígenas y de la sociedad civil en general, particularmente en relación a la investigación, la educación, y la intervención práctica en el campo de los servicios esenciales de agua y saneamiento, incluyendo su dimensión ecológico-ambiental.

\section{Principales prioridades identificadas en la VI Reunión PARA LA CONSTRUCCIÓN DE UNA POLÍTICA HÍDRICA IGUALITARIA}

1) Contribuir a la confrontación de las diversas formas de violencia ejercidas sobre las poblaciones mediante la implementación de procesos de mercantilización de las fuentes de agua y de los servicios públicos esenciales de agua y saneamiento, de la expansión desregulada y descontrolada de la minería a cielo abierto, de los grandes megaproyectos hidráulicos, incluyendo los proyectos energéticos basados en la tecnología de la fractura hidráulica (fracking), de los monocultivos transgénicos y su uso intensivo, frecuentemente no regulado y muchas veces ilegal, de agroquímicos/agrotóxicos, entre otros temas.

2) Apoyar las luchas contra los procesos mercantiles y privatistas que amenazan con la profundización del proceso de destrucción de la base de la vida, como son la monopolización de la producción de semillas por parte de empresas multinacionales y la consecuente reducción de la biodiversidad y la violación de la soberanía alimentaria de los pueblos.

3) Apoyar también las luchas por la defensa de los socioecosistemas fundantes de la vida, muchos de ellos bajo severa amenaza o en proceso franco de desaparición, como son los humedales, los páramos, los glaciares, los manglares, los manantiales, etc.

4) Luchar contras las formas visibles e invisibles de violencia relacionadas con la política y la gestión del agua, como las violencias represivas que se registran contra individuos y organizaciones que defienden los derechos de las poblaciones, de los trabajadores y de la ciudadanía en general, pero también contra las violencias simbólicas, epistémicas, emocionales, y de otras naturalezas que son ejercidas en los diversos espacios de actividad con el fin de legitimar políticas antidemocráticas y amedrentar a quienes defienden modelos de sociedad fundados en el ideal de la igualdad y rechazan la mercantilización de las relaciones sociales y de los procesos de la vida en general.

5) Defender el control y la gestión del agua como bien común, como bien público, como derecho humano, que debe estar en manos de empresas públicas y comunitarias, sujetas al control democrático, con transparencia en la gestión.

6) Denunciar y confrontar las estrategias y mecanismos utilizados por los agentes que promueven la profundización de los procesos de neoliberalización de la política y la gestión del agua y sus servicios. Tras el fracaso rotundo de las políticas promovidas desde la década de 1980, particularmente la privatización abierta de las fuentes y de los servicios de agua mediante concesiones de largo plazo 0 incluso en casos extremos como Chile e Inglaterra, la transferencia de la propiedad de las fuentes y de la infraestructura de los servicios de agua a empresas privadas, se han desarrollado una diversidad de nuevas tácticas para lograr el objetivo por otros medios. Una forma particularmente exitosa de forzar la mercantilización y la privatización del agua y sus servicios ha sido la celebración de acuerdos bi- y multi-laterales de 
VI Reunión de la Red WATERLAT-GOBACIT "Agua, violencia y utopías. ¿Cuáles son las prioridades para construir una política hídrica igualitaria?"

protección de las inversiones y de apertura del mercado de bienes y servicios. Un objetivo central de estas estrategias es el de anular la soberanía de los estados nacionales e impedir que la ciudadanía pueda ejercer sus derechos civiles, políticos y sociales plenamente, pues dichos acuerdos fundamentalmente garantizan el derecho de las empresas privadas, en general multinacionales, a la acumulación de ganancias con independencia virtualmente completa con respecto a sus obligaciones contractuales. Países como Argentina, para dar un ejemplo notorio, han perdido docenas de juicios ante el Centro Internacional de Arreglo de Diferencias Relativas a Inversiones (CIADI) del Banco Mundial, aun en el caso de juicios que involucran a empresas convictas de fraude en sus países de origen, como Estados Unidos 0 Francia, y que incumplieron sus contratos en el país. Los países centrales se encuentran en este momento en un proceso que busca consolidar esta verdadera dictadura del capital financiero por medio de la implementación de un nuevo instrumento de subordinación de la soberanía de los países a los intereses del capital por medio del Acuerdo General sobre Comercio de Servicios (AGCS), o Trade in Services Agreement (TiSA), en inglés. Es de fundamental importancia analizar, documentar y exponer las consecuencias concretas que este tipo de estrategias puede tener sobre los países del Sur Global, y notoriamente los de América Latina y el Caribe, que son un blanco privilegiado por estas políticas.

7) Luchar contra la corrupción privado-pública (CPP), que se manifiesta de muchas formas en el sector del agua y sus servicios. Es necesario transformar la percepción dominante que ha sido creada por las instituciones y los gobiernos que defienden una política del agua privatista y mercantil según la cual la corrupción es fundamentalmente pública, lo cual ha contribuido al descrédito de las instituciones públicas y de la política en general. Es necesario demostrar que la corrupción es endémica en las relaciones entre el estado y los actores privados y

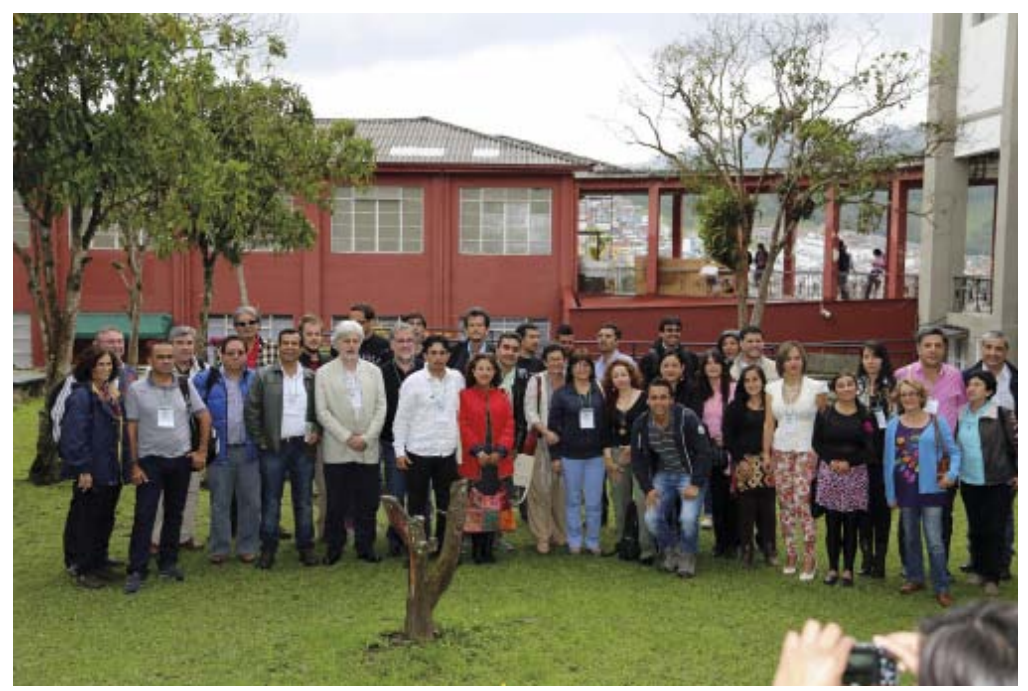

que frecuentemente es promovida por los propios actores nacionales e internacionales que levantan su dedo acusador contra la corrupción pública, como son las instituciones financieras internacionales y los gobiernos de los países centrales que mantienen un monopolio de la producción de "rankings" de transparencia y corrupción.

8) Promover y fortalecer las alianzas y asociaciones público-públicas, público-comunitarias y comunitario-comunitarias, y desarrollar otras formas, según pudiera corresponder, para el fortalecimiento de las luchas contra las amenazas al proceso de democratización de la política y la gestión del agua y para lograr la profundización de dicho proceso.

9) Concebir y fortalecer modelos innovadores de política y gestión del agua y sus servicios, que privilegien las prácticas inter-sectoriales, que rompan con las visiones tecno-céntricas dominantes, que se enmarquen en un enfoque de política pública democrática, con planificación de mediano y largo plazo, con participación social efectiva, no meramente formal, y con control democrático. Estos modelos deben promover la gestión pública y contar con mecanismos que impidan el uso de lo público como una fachada para encubrir procesos de mercantilización y de acumulación privada de la ganancia, como por ej emplo las "asociaciones público-privadas" (PPPs), la transferencia de acciones de empresas públicas a inversores privados, u otras formas.

10) Fortalecer el Área Temática 7 de la Red para desarrollar actividades de Arte, Comunicación, Cultura y Educación orientadas a promover la emergencia y consolidación de formas sociales que rompan con las lógicas mercantiles y privatistas y contribuyan a generar políticas, formas de gestión y de relación con el agua y sus servicios basados en el ideal de la igualdad.

11) Dar prioridad a los temas mencionados en los puntos anteriores en las actividades de investigación, docencia y acción práctica de la Red WATERLAT-GOBACIT, fomentando la X-disciplinaridad, tema de nuestra Área Temática 1, que consiste en la transgresión constructiva de los límites disciplinarios, en la generación de rupturas epistemológicas y en la incorporación de saberes diversos, incluyendo saberes que no se rigen por las normas de la ciencia convencional, en la producción de conocimiento teórico y empírico sobre el agua. Consolidar y profundizar la $X$ - disciplinaridad mediante alianzas entre actores académicos, organizaciones de trabajadores, movimientos sociales, representantes de comunidades y otros actores relevantes en la lucha por la democratización de la política y la gestión del agua y por la construcción de sociedades más humanas, fundadas en el ideal de la igualdad.

\section{José Esteban Castro}

Coordinador Red Waterlat-Gobacit 
